\title{
PRÍSTINO DE UNA INVESTIGACIÓN ACADÉMICA
}

\author{
PRISTINE FROM ACADEMIC RESEARCH \\ Edgar Gutiérrez Gómez ${ }^{1 *}$ \\ egutierrez@unah.edu.pe \\ ${ }^{1}$ Universidad Nacional Autónoma de Huanta, Ayacucho, Perú
}

*Correspondencia: Edgar Gutiérrez Gómez. Email: egutierrez@unah.edu.pe

La universidad es comunidad de docentes y académicos con libertad de pensamiento, que superaron los disímiles ciclos en su progreso histórico. Su existencia se justifica con su personal de entelequia, como la sentencia de Mariátegui: "A la Universidad le tocaba darle, por ende, esta milicia intelectual”. (2012, p,221). Independientemente, sobre el ego académico que hace competente a las universidades reinantes, como producto de una escolta minuciosa por la Superintendencia Nacional de Educación Superior Universitaria (SUNEDU) la investigación es determinante para redimir la razón de su existencia de estas universidades en su ámbito geográfico donde se ha erigido.

La Universidad Nacional Autónoma de Huanta (UNAH) con licencia institucional por la SUNEDU, justifica su funcionamiento que: "la Política de Investigación de la Universidad al tratarse de una universidad nueva necesita ser reforzada desde distintos aspectos, ello en función a que la investigación es un pilar fundamental en la educación superior universitaria”. (El peruano, 2017, p,10). En concordancia a su justificación para su fundación y, funcionamiento académico se construye el prístino de la publicación de sus trabajos de investigación en su revista institucional de investigación científica PURIQ. Los artículos seleccionados para este primer número son de absoluta responsabilidad de sus autores, quiénes voluntariamente cumplieron con los requisitos establecidos en su convocatoria para su publicación, además dejan a un escrutinio de la comunidad científica el producto de su investigación.

En circunstancias calamitosas donde las universidades, están rescindidas por no cumplir las condiciones básicas de calidad, exigidos por la SUNEDU, la UNAH apuesta en contribuir a la comunidad que los ha erigido como una institución académica de nivel superior competitiva con sus pares, a nivel nacional. No soslaya ni renuncia a las objeciones de elementos anacrónicos que se difumina en la multitud, se apuesta a estilo férreo de Bertrand Russell cuando fue cuestionado su nombramiento como docente en la Universidad de la Ciudad de Nueva York: "Los grandes espíritus —advirtió Einstein—, han hallado siempre violenta oposición de parte de las mediocridades”. (Russel, 1979, p,120). Bien sustentado en el apéndice de su trabajo de Russell, defendido por reputados científicos de su época.

\section{REFERENCIAS BIBLIOGRÁFICAS}

El peruano (2017). Resolución del Consejo Directivo No 014-2017-SUNEDU/CD Publicado el 19 de abril. (16-06-19). https://drive.google.com/file/d/1tKrxJ57bVPhWrs_v CN8MUJHzPlrQMSlt/view 
Mariátegui, J. C. (2014). Siete ensayos de interpretación de la realidad peruana. Retrieved from https://ebookcentral.proquest.com

Russell, B. (1979). Por qué no soy cristiano. Barcelona. Hispano Americana, S.A. (EDHASA)

\section{CITAR COMO:}

Gutiérrez Gómez, E. (2019). Prístino de una investigación académica. Puriq, 1(01), 1-2. https://doi.org/10.37073/puriq.1.01.53 